
\title{
25 Research Soure \\ SLC16A1 SNPs and leisure-time physical activity in young Brazilian adults
}

\section{Fernando Pires Hartwig}

Universidade Federal de Pelotas

Rafaela Martins ( $\nabla$ rafamartins1@gmail.com )

Universidade Federal de Pelotas https://orcid.org/0000-0003-3538-7228

\section{Bernardo Lessa Horta}

Universidade Federal de Pelotas

Airton Rombaldi

Universidade Federal de Pelotas

Ulf Ekelund

Norwegian School of Sport Sciences/University of Cambridge

\section{Denise Petrucci Gigante}

Universidade Federal de Pelotas

\section{Pedro Curi Hallal}

Universidade Federal de Pelotas

\section{Research}

Keywords: Motor activity, Lactate clearance, Single Nucleotide Polymorphisms

Posted Date: March 26th, 2020

DOI: https://doi.org/10.21203/rs.3.rs-18845/v1

License: (c) (i) This work is licensed under a Creative Commons Attribution 4.0 International License.

Read Full License 


\section{Abstract}

Background: Physical inactivity is a pandemic risk factor for non-communicable diseases. Investigating its determinants is critical to inform effective interventions. However, little is known about genetic determinants of physical activity.

Methods: Adults from 1982 Pelotas Birth Cohort were investigated. Five SLC16A1 SNPs were assessed for association with physical activity measured by the International Physical Activity Questionnaire.

Results: At a mean age of 22.8 years, rs1049434-AT and TT genotypes (compared to AA) were associated with 4.9 (95\% Cl: $-32.8 ; 41.5)$ and $20.6(-29.1 ; 69.4)$ more minutes per week of self-reported leisuretime physical activity in males, respectively. rs3849174-AT and TT males reported 7.9 (95\% Cl: -43.1; 27.3) and 41.6 (95\% Cl: $-111.5 ; 28.2)$ less minutes per week compared to AA, respectively. At a mean age of 30.2 years, the results for the rs 1049434 in males were very similar. Effect estimates of 22.6 (95\% Cl: 53.8; 8.6) and 28.7 (95\% Cl: -90.8; 33.4) less minutes were observed for rs3849174-TG and GG males, respectively. Results were inconsistent for the rs17493313 SNP and for females.

Conclusion: Our results suggest that rs1049434 and rs3849174 SNPs may be genetic determinants of physical activity. However, our findings need replication in larger samples with more precise measures of physical activity.

\section{Introduction}

The pandemic of physical inactivity (16) is causing more than 5 million annual deaths worldwide (18). Even so, $1 / 3$ of the world's adult population fails to reach the recommended 150 minutes per week of at least moderate intensity physical activity, and an alarming $4 / 5$ of the adolescent population may be characterized as physically inactive according to public health recommendations (9). A better understanding of the determinants of physical activity at the population level is urgent and essential to help change this negative scenario (1).

So far, research into the correlates and determinants of physical activity has primarily focused on sociodemographic, intrapersonal, interpersonal and environmental factors and the vast majority of data are from high-income countries (1). However, some previous studies have identified genetic factors associated with different aspects of physical activity. Genetic variation [especially single nucleotide polymorphisms (SNPs)] in genes involved with biological processes physiologically related to physical activity has been studied in different high-level athletic contexts in distinct populations, likewise in laboratory studies and specific designs such as twin studies $(1,5,15)$.

Family and twin studies assessing physical activity heritability have provided estimates with high variation in different populations, as described previously $(1,7)$. Such variability could be attributed to different factors, from population differences to measurement error. A twin study using objectivelymeasured physical activity and sedentary behavior obtained heritability estimates of $47 \%$ and $31 \%$ for 
time spent in moderate-to-vigorous intensity physical activity and in sedentary behavior, respectively (7). Although some candidate genes have been proposed, including MC4R $(20), \operatorname{LEPR}(19,28)$ and DRD2 $(25)$, the genetic architecture underlying the heritable component of physical activity remains largely unidentified (6). While there are currently no robust variants identified through genome-wide association studies, candidate-gene studies can contribute to identify biological pathways involved with physical activity predisposition, as well as replicate and refine findings from genome-wide investigations (once these are available) in different populations.

Genetic factors involved with of lactate accumulation are possibly associated with predisposition to being physically active in the general population. More specifically, lactate levels are well-established markers of oxygen supply to the tissues, which influences muscle fatigue (13). This then may influence an individuals' motivation to exercise (1). Genetic variation in the SLC16A1 gene (which encodes the lactate transporter protein monocarboxylate transporter 1) was identified in patients with lactate transport deficiency (22). Later, this gene was screened for genetic variation in a Singaporean sample (17) and one of the identified variants has been associated with lactate accumulation after exercise $(3,4$, $8)$, and with athletic performance $(8,24)$.

In spite of the plausible link between genetic variation in genes involved with lactate clearance and physical activity and the corroborative evidence in specific groups of athletes, no population-based investigation examining the potential association between this gene and physical activity has been performed to date. The aim of the present study was to investigate the association between SLC16A1 SNPs and physical activity levels in a population-based sample of young Brazilian adults.

\section{Methods}

\section{Study participants and data collection}

In 1982, the maternity hospitals in Pelotas, a southern Brazilian city (current population 330,000), were visited daily and screened for all newborns. In total 5914 live births whose families lived in the urban area were examined and their mothers interviewed. Information of more than $99 \%$ of the live births was collected $(n=2898)$. Individuals belonging to the birth cohort were thereafter followed up at the mean ages of $11.3,19.4$ and 43.1 months, and 13.1, 14.7, 18.2, 18.9, 22.8 and 30.2 years of age. Details about the methods of the 1982 Pelotas (Brazil) Birth Cohort study are available elsewhere $(14,30)$.

From October 2004 to August 2005 (mean age of 22.8 years), we visited participants in their households. In this visit, physical activity levels were assessed via self-report using the long version of the International Physical Activity Questionnaire (2). This questionnaire measures moderate- and vigorousintensity physical activities lasting for at least 10 consecutive minutes in four domains: leisure-time, occupation, transportation and housework. For the purpose of this article, we only analyzed data on leisure-time physical activity to be compared with the 30 years follow-up. A score of leisure-time physical 
activity was constructed as follows: minutes per week of walking + minutes per week of moderateintensity physical activity + minutes per week of vigorous-intensity physical activity multiplied by 2 .

From June 2012 to February 2013 (mean age of 30.2 years), all cohort participants were invited to visit the research clinic to be interviewed and examined. In this visit, leisure-time physical activity was obtained from a list of 12 different types of indoor and outdoor physical activities and three additional questions concerning other activities. This instrument was tested in a pilot study involving 70 volunteers of about 30 years of age. The 12 activities included represented $95 \%$ of the type of activities practiced by the volunteers. Individuals were asked about frequency and duration of each activity. Leisure-time physical activity during time was obtained by summing weekly time in minutes spent in each activity.

Both visits were approved by the Ethics Committee of the Medical School of Federal University of Pelotas (protocol numbers 20/2003 and 16/2012). Written informed consent was obtained.

\section{Genotyping and SNPs selection}

At the 22 years follow up visit, subjects were also invited to visit the research laboratory to donate a blood sample, collected by venous puncture. DNA was extracted and frozen at $-70^{\circ} \mathrm{C}$. DNA samples were genotyped using the Illumina HumanOmni2.5-8v1 array. From SNPs that remained after quality control

[exclusion criteria: Hardy-Weinberg Equilibrium (HWE) P-value $<1 \times 10^{-8}$, minor allele frequency $\leq 1 \%$ and genotyping rate $\leq 90 \%$ )], the ones that lie within SLC16A1 (genome assembly GRCh37.p13) region (from start to stop codons, including introns) and that are uniquely mapped to this gene were selected, resulting in five SNPs: rs17493313, rs9429505, rs7169, rs1049434 and rs3849174.

\section{Statistical analyses}

Linkage disequilibrium (LD) analyses were performed by calculating $r^{2}$ values of all pairwise combinations of SNPS. HWE and distribution of the genotypes of each SNP according to observed skin color were evaluated by Fisher's exact and $\chi^{2}$ tests, respectively. Crude and adjusted associations between each SNP and physical activity were evaluated by linear regression. Adjusted analyses controlled for the top 20 ancestry-informative principal components (calculated using a LD-pruned subset of 300000 autosomal SNPs), and were also stratified by sex.

Due to positive skewness in physical activity scores, we repeated some analyses using bootstrap to estimate effect sizes, confidence intervals and P-values. Because findings using bootstrap were virtually identical to those using classical linear regression, we opted to present only the latter (bootstrap results available upon request). Statistical significance was a priori defined as $\mathrm{P}<0.05$. Principal components were calculated using SNP \& Variation Suite version 7.7.8 (Golden Helix). The remaining analyses were performed using R version 3.0.2 (http://www.r-project.org/).

\section{Results}

\section{Sample description}


In the 2012-13 (30-31 years of age) follow up visit, we were able to locate 3701 individuals, which (added to the 325 known to have died) represent a follow-up rate of $68.1 \%$. Follow-up rates were slightly lower among males, individuals in the wealthiest socioeconomic groups at birth and with normal birth weight (Table 1). When compared to the entire 2012-2013 follow-up participants, individuals with both genetic and physical activity data were poorer and less active in their leisure-time at a mean age of 30.2 years. 
Table 1

Comparison of the cohort at baseline with the 2012-2013 follow-up, and of the later with the studied sample. Values are percentages.

\begin{tabular}{|c|c|c|c|}
\hline $\begin{array}{l}\text { Age at } \\
\text { follow-up }\end{array}$ & Variables & $\begin{array}{l}\text { \% followed-up in } \\
2012-2013^{a}\end{array}$ & $\begin{array}{l}\text { \% studied among 2012- } \\
2013 \text { follow-up }{ }^{b}\end{array}$ \\
\hline \multirow[t]{3}{*}{ At birth } & Sex & & \\
\hline & Males & 65.2 & 77.1 \\
\hline & Females & 71.1 & 79.5 \\
\hline \multirow[t]{6}{*}{ At birth } & $\begin{array}{l}\text { Family income at birth (minimum } \\
\text { wages) }\end{array}$ & & \\
\hline & $\leq 1.0$ & 68.0 & 78.6 \\
\hline & $1.1-3.0$ & 70.5 & 79.5 \\
\hline & $3.1-6.0$ & 66.1 & 79.0 \\
\hline & $6.1-10.0$ & 62.8 & 73.4 \\
\hline & $>10.0$ & & \\
\hline \multirow[t]{5}{*}{ At birth } & $\begin{array}{l}\text { Maternal schooling at birth } \\
\text { (complete years) }\end{array}$ & 66.1 & 76.6 \\
\hline & $0-4$ & 70.4 & 79.7 \\
\hline & $5-8$ & 69.3 & 78.9 \\
\hline & $9-11$ & 61.3 & 73.4 \\
\hline & 12 or more & 60.3 & 73.3 \\
\hline \multirow[t]{4}{*}{ At birth } & $\begin{array}{l}\text { Maternal smoking during } \\
\text { pregnancy (\# cigarettes) }\end{array}$ & & \\
\hline & Have not smoked & 68.0 & 77.7 \\
\hline & $1-14$ & 68.5 & 79.2 \\
\hline & 15 or more & 67.2 & 79.9 \\
\hline At birth & Birthweight (g) & & \\
\hline
\end{tabular}

Studied sample: individuals with both physical activity (in both follow-up visits) and genetic data.

PA: Physical activity.

a Individuals known to have died were included both in the numerator and in the denominator.

${ }^{\mathrm{b}}$ Individuals known to have died were not considered in this calculation. 


\begin{tabular}{|c|c|c|c|}
\hline $\begin{array}{l}\text { Age at } \\
\text { follow-up }\end{array}$ & Variables & $\begin{array}{l}\text { \% followed-up in } \\
2012-2013^{a}\end{array}$ & $\begin{array}{l}\text { \% studied among 2012- } \\
2013 \text { follow-up }\end{array}$ \\
\hline & $<2500$ & 72.1 & 67.4 \\
\hline & $\geq 2500$ & 67.7 & 79.2 \\
\hline \multirow[t]{6}{*}{30.2} & \multicolumn{3}{|l|}{ Household asset index (quintiles) } \\
\hline & Poorest & - & 78.6 \\
\hline & 2 nd & - & 78.2 \\
\hline & $3 r d$ & - & 79.7 \\
\hline & 4th & - & 84.1 \\
\hline & Wealthiest & - & 76.0 \\
\hline \multirow[t]{5}{*}{30.2} & \multicolumn{3}{|l|}{$\begin{array}{l}\text { Achieved schooling (complete } \\
\text { years) }\end{array}$} \\
\hline & $0-4$ & - & 79.4 \\
\hline & $5-8$ & - & 76.0 \\
\hline & $9-11$ & - & 80.1 \\
\hline & 12 or more & - & 78.4 \\
\hline \multirow[t]{4}{*}{22.8} & \multicolumn{3}{|l|}{ Leisure-time PA (min/week) } \\
\hline & 0 & - & 85.3 \\
\hline & $1-149$ & - & 86.2 \\
\hline & $\geq 150$ & - & 85.4 \\
\hline \multirow[t]{4}{*}{30.2} & \multicolumn{3}{|l|}{ Leisure-time PA (min/week) } \\
\hline & 0 & - & 80.7 \\
\hline & $1-149$ & - & 78.9 \\
\hline & $\geq 150$ & - & 75.1 \\
\hline \multicolumn{4}{|c|}{ Studied sample: individuals with both physical activity (in both follow-up visits) and genetic data. } \\
\hline \multicolumn{4}{|c|}{ PA: Physical activity. } \\
\hline \multicolumn{4}{|c|}{ andividuals known to have died were included both in the numerator and in the denominator. } \\
\hline
\end{tabular}


Table 2 provides a description of the studied sample. $47.5 \%$ of the individuals were males and more than $70 \%$ reported white skin color. The frequencies of the homozygous variant genotype (i.e., the genotype with two copies of the least prevalent allele) varied between $2.9 \%$ than $15.5 \%$ regarding the three SNPs selected based on LD (see next paragraph). Men were more active and women for all physical activity measurements. As expected, the differences between the mean and the median for physical activity variables indicate a substantial positive skewness. 
Table 2

Description of the studied sample. Values are percentages for categorical variables, and mean (standard deviation) and median (interquartile range) for continuous variables.

\begin{tabular}{|c|c|c|c|c|c|}
\hline $\begin{array}{l}\text { Age at } \\
\text { follow- } \\
\text { up }\end{array}$ & Variables & Total & Males & Females & P-value ${ }^{a}$ \\
\hline \multirow[t]{5}{*}{22.8} & Skin color & & & & \\
\hline & White & 76.2 & 75.7 & 76.6 & 0.59 \\
\hline & Brown & 5.6 & 6.2 & 5.0 & \\
\hline & Black & 14.8 & 14.7 & 15.0 & \\
\hline & Other ${ }^{b}$ & 3.4 & 3.4 & 3.4 & \\
\hline \multirow[t]{4}{*}{22.8} & rs 17493313 & & & & \\
\hline & $\mathrm{T} / \mathrm{T}$ & 68.0 & 68 & 68.0 & 0.844 \\
\hline & $\mathrm{T} / \mathrm{C}$ & 29.1 & 29.3 & 28.9 & \\
\hline & $\mathrm{C} / \mathrm{C}$ & 2.9 & 2.7 & 3.1 & \\
\hline \multirow[t]{4}{*}{22.8} & rs1049434 & & & & \\
\hline & $A / A$ & 38.2 & 37.6 & 38.7 & 0.273 \\
\hline & $\mathrm{A} / \mathrm{T}$ & 46.3 & 45.7 & 46.8 & \\
\hline & $\mathrm{T} / \mathrm{T}$ & 15.5 & 16.7 & 14.5 & \\
\hline \multirow[t]{4}{*}{22.8} & rs3849174 & & & & \\
\hline & $\mathrm{T} / \mathrm{T}$ & 55.9 & 56.9 & 55.0 & 0.582 \\
\hline & $\mathrm{T} / \mathrm{G}$ & 37.2 & 36.2 & 38.0 & \\
\hline & $\mathrm{G} / \mathrm{G}$ & 6.9 & 6.9 & 7.0 & \\
\hline \multirow[t]{3}{*}{22.8} & Leisure-time PA (min/week) & & & & \\
\hline & Mean (SD) & $145.9(256.2)$ & 219.7 (308.0) & 79.1 (172.9) & $<0.001$ \\
\hline & Median (IQR) & $40.0(180.0)$ & $120.0(300.0)$ & $0.0(80.0)$ & $<0.001$ \\
\hline
\end{tabular}

PA: Physical activity.

${ }^{a}$ Test for association between each variable ( $\chi^{2}$ test for categorical or Student's T-test and Wilcoxon rank-sum test for continuous) and sex.

bother: Asian ( $n=53 ; 53.5 \%)$ and Native-American $(n=46 ; 46.5 \%)$. 


\begin{tabular}{|c|c|c|c|c|c|}
\hline $\begin{array}{l}\text { Age at } \\
\text { follow- } \\
\text { up }\end{array}$ & Variables & Total & Males & Females & P-value ${ }^{a}$ \\
\hline \multirow[t]{4}{*}{30.2} & \multicolumn{5}{|c|}{ Leisure-time PA (min/week) } \\
\hline & Mean (SD) & $131.5(224.7)$ & $188.0(271.7)$ & $80.7(155.2)$ & $<0.001$ \\
\hline & Median (IQR) & $22.5(180.0)$ & $80.0(260)$ & $0.0(120.0)$ & $<0.001$ \\
\hline & Total & 2898 & 1377 & 1521 & \\
\hline \multicolumn{6}{|c|}{ PA: Physical activity. } \\
\hline \multicolumn{6}{|c|}{$\begin{array}{l}\text { aTest for association between each variable ( } \chi^{2} \text { test for categorical or Student's T-test and Wilcoxon } \\
\text { rank-sum test for continuous) and sex. }\end{array}$} \\
\hline
\end{tabular}

\section{SLC16A1 SNPs architecture and distribution according to skin color}

LD analyses revealed three distinct high-LD blocks $\left(r^{2}>0.900\right)$ among SLC16A1 SNPs (data not shown). Therefore, one SNP of each block (rs17493313, rs1049434 and rs3849174) was selected for further analyses. Associations between each SNP and skin color, as well as HWE analysis, are shown in Table 3. As expected, the genotypic frequencies of the three SNP varied significantly according to skin color ( $\mathrm{P}=$ $0.011, P<0.001$ and $P<0.001$ for rs 17493313, rs1049434 and rs3849174, respectively). No significant deviances from HWE were observed for rs17493313 and rs1049434 in the total sample and within skin color strata. However, rs3849174 presented a significant deviance from HWE within blacks $(P=0.044)$. Therefore, all association analyses involving rs3849174 were performed for all skin color groups and within non-blacks only to avoid the possibility of finding spurious associations. 
Table 3

SLC16A1 SNPs frequencies and HWE according to self-reported skin color. Values are row percentages.

\begin{tabular}{|c|c|c|c|c|c|c|}
\hline \multirow[t]{2}{*}{ SNP } & \multirow[t]{2}{*}{ Skin color } & \multicolumn{3}{|c|}{ Genotypes } & \multicolumn{2}{|c|}{ P-value } \\
\hline & & & & & HWE $^{\mathrm{a}}$ & $x^{2 b}$ \\
\hline \multirow[t]{5}{*}{ rs17493313 } & & $\mathrm{T} / \mathrm{T}$ & $\mathrm{T} / \mathrm{C}$ & $\mathrm{C} / \mathrm{C}$ & 0.605 & 0.011 \\
\hline & White $(N=2208)$ & 66.6 & 30.4 & 3.0 & 0.431 & \\
\hline & Brown $(\mathrm{N}=161)$ & 77.0 & 19.9 & 3.1 & 0.152 & \\
\hline & Black $(\mathrm{N}=430)$ & 73.0 & 24.7 & 2.3 & 0.702 & \\
\hline & Other ${ }^{\mathrm{C}}(\mathrm{N}=99)$ & 63.3 & 35.7 & 1.0 & 0.181 & \\
\hline \multirow[t]{5}{*}{ rs1049434 } & & $\mathrm{A} / \mathrm{A}$ & $\mathrm{A} / \mathrm{T}$ & $\mathrm{T} / \mathrm{T}$ & 0.210 & $<0.001$ \\
\hline & White $(N=2208)$ & 35 & 48.1 & 16.9 & 0.792 & \\
\hline & Brown $(\mathrm{N}=161)$ & 37.3 & 50.9 & 11.8 & 0.313 & \\
\hline & Black $(\mathrm{N}=430)$ & 54.7 & 36.7 & 8.6 & 0.178 & \\
\hline & Other $^{\mathrm{C}}(\mathrm{N}=99)$ & 39.4 & 40.4 & 20.2 & 0.142 & \\
\hline \multirow[t]{5}{*}{ rs3849174 } & & $\mathrm{T} / \mathrm{T}$ & $\mathrm{T} / \mathrm{G}$ & $\mathrm{G} / \mathrm{G}$ & 0.240 & $<0.001$ \\
\hline & White $(N=2208)$ & 59.7 & 35.5 & 4.8 & 0.502 & \\
\hline & Brown $(\mathrm{N}=161)$ & 51.6 & 42.8 & 5.7 & 0.420 & \\
\hline & Black $(N=430)$ & 38.7 & 43.1 & 18.2 & 0.044 & \\
\hline & Other $^{\mathrm{C}}(\mathrm{N}=99)$ & 53.5 & 39.4 & 7.1 & $>0.999$ & \\
\hline \multicolumn{7}{|c|}{$\begin{array}{l}\text { aExact Hardy-Weinberg Equilibrium test. The first (from top to bottom) P-value for each SNP } \\
\text { corresponds to the total sample. }\end{array}$} \\
\hline \multicolumn{7}{|c|}{${ }^{b} \chi^{2}$ test of the association between genotype frequencies and self-reported skin color. } \\
\hline
\end{tabular}

\section{Associations of SLC16A1 SNPs with physical activity}

To test the hypothesis that genetic variation in SLC16A1 is associated with physical activity in the general population, crude and adjusted analyses involving rs17493313, rs1049434 and rs3849174 SNPs and physical activity were performed. 
Table 4 displays the associations between each of the three SNPs and leisure-time physical activity at a mean age of 22.8 years. For the rs 17493313 SNP, the CC genotype was related to lower levels of physical activity: in adjusted analyses, males presenting the CC genotype reported, on average, $59.2(95 \% \mathrm{Cl}$ : $-160.0 ; 42.4)$ less minutes per week of leisure-time physical activity as compared to TT individuals, while females presented 23.0 (95\% Cl: -74.5; 28.4) less minutes. Regarding the rs1049434 SNP, AT males compared to AA - reported 4.9 (95\% Cl: $-31.8 ; 41.5)$ more minutes per week, and TT reported 20.6 (95\% Cl: $-28.1 ; 69.4)$ more minutes. This pattern (less activity according to the number of T alleles) was not observed in females. For the rs3849174 SNP, TG and GG males reported 7.9 (95\% Cl: $-43.1 ; 27.3)$ and 41.6 (95\% Cl: $111.5 ; 28.2)$ less minutes per week of leisure-time physical activity when compared to TT.

Females carrying the $\mathrm{G}$ allele also reported less activity when compared to $\mathrm{TT}$, but the magnitude of the effect did not increase according to the number of $\mathrm{G}$ alleles.

Table 4

Linear regression coefficients for leisure-time physical activity (min/week) at a mean age of 22.8 years according to SLC16A1 SNPs $\pm 95 \% \mathrm{Cl}$

\begin{tabular}{|lllll|}
\hline SNP & Crude & \multicolumn{2}{ll}{ Adjusted for ancestry-informative principal components } \\
\hline & & Entire sample & Males & Females \\
\hline rs17493313 & $\mathrm{P}=0.299$ & $\mathrm{P}=0.352$ & $\mathrm{P}=0.472$ & $\mathrm{P}=0.561$ \\
\hline T/T & 0 (Ref.) & 0 (Ref.) & 0 (Ref.) & 0 (Ref.) \\
\hline T/C & $-1.1(-21.9 ; 19.6)$ & $-0.1(-21.0 ; 20.8)$ & $5.8(-30.4 ; 42.0)$ & $-7.2(-26.8 ; 12.4)$ \\
\hline C/C & $-44.6(-101.0 ; 11.7)$ & $-41.5(-98.1 ; 15.1)$ & $-59.2(-160.8 ; 42.4)$ & $-23.0(-74.5 ; 28.4)$ \\
\hline rs1049434 & $\mathrm{P}=0.114$ & 0.105 & $\mathrm{P}=0.704$ & $\mathrm{P}=0.051$ \\
\hline A/A & $0($ Ref. $)$ & $0($ Ref. $)$ & $0($ Ref. $)$ & $0($ Ref. $)$ \\
\hline A/T & $-2.4(-22.8 ; 18.0)$ & $-1.7(-22.4 ; 19.1)$ & $4.9(-31.8 ; 41.5)$ & $-11.6(-30.9 ; 7.6)$ \\
\hline T/T & $25.9(-2.1 ; 54.0)$ & $27.2(-1.5 ; 55.8)$ & $20.6(-28.1 ; 69.4)$ & $20.4(-7.0 ; 47.7)$ \\
\hline rs3849174 & $P=0.284$ & $P=0.238$ & $P=0.498$ & $P=0.531$ \\
\hline T/T & $0($ Ref. $)$ & $0($ Ref. $)$ & $0($ Ref. $)$ & $0($ Ref. $)$ \\
\hline T/G & $-12.2(-32.0 ; 7.5)$ & $-13.5(-33.6 ; 6.6)$ & $-7.9(-43.1 ; 27.3)$ & $-10.7(-29.4 ; 8.1)$ \\
\hline G/G & $-24.1(-61.7 ; 13.6)$ & $-27.2(-66.6 ; 12.2)$ & $-41.6(-111.5 ; 28.2)$ & $-2.4(-38.9 ; 34.1)$ \\
\hline
\end{tabular}

Associations involving leisure-time physical activity at a mean age of 30.2 years are shown in Table 5 . rs17493313 estimates presented inconsistent directions for males when compared to Table 4; the pattern (i.e., change in regression coefficients according to the number of $\mathrm{C}$ alleles) was inconsistent in both sexes, and the magnitude of the estimates was considerably smaller. Estimates for rs 1049434 were inconsistent for females, but similar in direction and magnitude for males: when compared to AA, AT and 
TT individuals reported 3.9 (95\% Cl: -28.6; 36.5) and $19.0(-24.4 ; 62.4)$ more minutes per week of leisuretime physical activity. Females also presented inconsistent results for the rs3849174 SNP, while males presented consistent directions. Although less activity being reported according to the number of $\mathrm{G}$ alleles was also observed at a younger age, there difference between effect estimates of TG and GG individuals was smaller at a mean age of 30.2 years.

Table 5

Linear regression coefficients for leisure-time physical activity (min/week) at a mean age of 30.2 years according to SLC16A1 SNPs

\begin{tabular}{|lllll|}
\hline SNP & Crude & \multicolumn{2}{ll}{ Adjusted for ancestry-informative principal components } \\
\hline & & Entire sample & Males & Females \\
\hline rs17493313 & $\mathrm{P}=0.549$ & $\mathrm{P}=0.553$ & $\mathrm{P}=0.509$ & $\mathrm{P}=0.888$ \\
\hline T/T & 0 (Ref.) & 0 (Ref.) & 0 (Ref.) & 0 (Ref.) \\
\hline T/C & $-10.1(-28.5 ; 8.3)$ & $-9.9(-28.4 ; 8.6)$ & $-18.9(-51.1 ; 13.3)$ & $-4.4(-22.2 ; 13.4)$ \\
\hline C/C & $-7.5(-57.8 ; 42.8)$ & $-10.1(-60.5 ; 40.3)$ & $-12.8(-104.4 ; 78.9)$ & $-1.1(-47.7 ; 45.5)$ \\
\hline rs1049434 & $\mathrm{P}=0.491$ & $\mathrm{P}=0.482$ & $\mathrm{P}=0.684$ & $\mathrm{P}=0.262$ \\
\hline $\mathrm{A} / \mathrm{A}$ & $0($ Ref. $)$ & $0($ Ref. $)$ & $0($ Ref. $)$ & $0($ Ref. $)$ \\
\hline $\mathrm{A} / \mathrm{T}$ & $-6.5(-24.6 ; 11.6)$ & $-5.3(-23.7 ; 13.1)$ & $3.9(-28.6 ; 36.5)$ & $-14.5(-32.0 ; 2.9)$ \\
\hline T/T & $7.7(-17.2 ; 32.6)$ & $9.5(-15.8 ; 34.9)$ & $19.0(-24.4 ; 62.4)$ & $-6.9(-31.6 ; 17.9)$ \\
\hline rs3849174 & $\mathrm{P}=0.299$ & $\mathrm{P}=0.256$ & $\mathrm{P}=0.307$ & $\mathrm{P}=0.636$ \\
\hline T/T & $0($ Ref. $)$ & $0($ Ref. $)$ & $0($ Ref. $)$ & $0($ Ref. $)$ \\
\hline T/G & $-13.8(-31.3 ; 3.7)$ & $-14.9(-32.7 ; 2.8)$ & $-22.6(-53.8 ; 8.6)$ & $-4.9(-21.8 ; 12.1)$ \\
\hline G/G & $-2.8(-36.2 ; 30.5)$ & $-8.3(-43.1 ; 26.6)$ & $-28.7(-90.8 ; 33.4)$ & $10.3(-22.8 ; 43.3)$ \\
\hline
\end{tabular}

\section{Discussion}

We investigated the association of genetic variation in SLC16A1 with leisure-time physical activity in a population-based sample with appreciable score-lowering effect estimates, but $95 \%$ Cls were wide. Results were more consistent for males than for females, and the SNP rs1049434 presented the most consistent results.

To the best of the authors' knowledge, this is the first investigation of an association between genetic variation in SLC16A1 and physical activity in the general population. Furthermore, this is the first candidate-gene assessment of the associations of SLC16A1 SNPs other than rs1049434 with physical activity. To date, there are only four reports of associations between rs1049434 and physical activity. The 
first reported an association between the SNP and lactate accumulation and maximum lactate concentration in 10 men aged 20-26 under controlled high-intensity circuit training (3). Later, a study in 15 men and 14 women observed an association between rs1049434 and blood lactate accumulation during different training series in males but not in females (4). Two recent studies provided further evidence on this topic: one observed a higher prevalence of the A allele in endurance-oriented athletes than in non-athletic individuals, while mean blood lactate levels were higher in male rowers carrying the Tallele than in AA ones (8); the other provided evidence that sprint/power athletes $(n=100)$ were more likely than endurance athletes $(n=112)$ and matched controls $(n=621)$ to present the T allele $(24)$.

Our findings agree with previously published studies regarding the general notion that SLC16A1 SNPs influence physical activity. Although effect estimates were larger for the rs3849174 SNP, the rs1049434 variant (which was associated with different aspects of physical activity in the aforementioned studies) presented very consistent effect estimates in males. However, the literature supports that rs1049434-T allele is associated with reduced predisposition to be physically active, but we observed the opposite. Additionally, an association was observed in females but not in males, which also is contrary to available evidence (4). However, women have consistently been reported to be less active (regarding overall and leisure-time physical activity) than men (1) and some data suggest women are less motivated to exercise $(21,29)$. If SLC16A1 SNPs influence exercise levels - a component of leisure-time physical activity lower participation in structured exercise in women may explain the sex differences observed.

Nevertheless, the inconsistencies with the literature evidence the need of future population-based studies in different genetic backgrounds to evaluate the association of these SNPs with leisure-time physical activity and whether this association is different between sexes.

One of the important limitations of our study is the use of self-reported physical activity. In this regard, we have focused on leisure-time physical activity for two reasons. First, it is well-known that occupational and housework domains are overestimated by IPAQ in Latin America (11). Second, the roles of genetic determinants are likely to be more pronounced in leisure-time than in transport-related physical activity, especially in low/middle income populations, where transport-related physical activity is likely determined by socioeconomic factors rather than individual choice (10). Moreover, given Mendel's 1st and 2nd laws $(26,27)$, it is unlikely that germline genetic variants (including SNPs) are associated with potential sources of systematic error in physical activity reports. Another potential source of bias in our study is the fact that our sample is multi-ethnic. However, ancestry-informative principal components obtained from genome-wide genotyping data were available and are known to provide a robust protection against population stratification (23). It is also reassuring that the results for the overall sample were similar comparing crude and adjusted analysis.

Although two SNPs (especially rs1049434) presented consistent results in males at different ages, our study is likely underpowered. Some causes of this limitation include measurement error of questionnaire measurers of physical activity (12), the multi-factorial nature of this behavior (1) and the low effect sizes frequently observed for common genetic variants. In the future (when the effects of life-long physical activity patterns will be more apparent in our cohort) it will also be possible to test the association of 
these SNPs with physical activity-related traits as an additional replication strategy, evaluating the effects of these SNPs on physical activity at different ages. However, the wide confidence intervals we observed do not allow excluding the possibility that our findings are due to chance. Although the associations we reported have biological plausibility, replication in other populations is warranted.

Considering that physical inactivity is a major risk factor for non-communicable diseases, identifying its correlates and determinants may have important public health impacts by providing evidence for effective interventions. In contrast to other factors such as socioeconomic characteristics, the current knowledge regarding the effects of genetic factors on physical activity levels is still modest. Although germline genetic factors are not subject to interventions, their study is important to understand causes of physical inactivity as well as variation in physical activity levels among populations and population subgroups. Our findings indicate that rs1049434 and rs3849174 SNPs are possibly associated with leisuretime physical activity in males in the general population, but this notion needs to be tested in additional population-based studies.

\section{Abbreviations}

PA: physical activity

SNPs: single nucleotide polymorphisms

HWE: Hardy-Weinberg Equilibrium

LD: linkage disequilibrium

\section{Declarations}

Ethics approval and consent to participate: Both visits were approved by the Ethics Committee of the Medical School of Federal University of Pelotas (protocol numbers 20/2003 and 16/2012). Written informed consent was obtained from all participants.

Competing interests: The authors declare no conflict of interests

Funding Source: Funding for genome-wide genotyping was received from the Brazilian Ministry of Health (Department of Science and Technology) as part of the EPIGEN-Brazil Consortium. Wellcome Trust funded the 1982 Pelotas Birth Cohort data collection presented in this study.

Authors contribution: $\mathrm{FPH}, \mathrm{BLH}$ and PCH conceived the idea and analyzed the data. FPH and RCM wrote the entire draft. All authors carefully reviewed the final manuscript.

Availability of data and materials: The data from this article are available with the corresponding author, upon reasonable request. 
Consent for publication: Not applicable.

Acknowledgements: This article is based on data from the study "Pelotas Birth Cohort, 1982" conducted by Postgraduate Program in Epidemiology at Universidade Federal de Pelotas with the collaboration of the Brazilian Public Health Association (ABRASCO). From 2004 to 2013, the Wellcome Trust supported the 1982 birth cohort study. The International Development Research Center, World Health Organization, Overseas Development Administration, European Union, National Support Program for Centers of Excellence (PRONEX), the Brazilian National Research Council (CNPq), and the Brazilian Ministry of Health supported previous phases of the study.

\section{References}

1. Bauman AE, Reis RS, Sallis JF, Wells JC, Loos RJF, Martin BW. Correlates of physical activity: why are some people physically active and others not? Lancet. 2012;380:258-71.

2. Craig CL, Marshall AL, Sjostrom M, Bauman AE, Booth ML, Ainsworth BE, Pratt M, Ekelund U, Yngve A, Sallis JF, Oja P. International physical activity questionnaire: 12-country reliability and validity. Med Sci Sports Exerc. 2003;35:1381-95.

3. Cupeiro R, Benito PJ, Maffulli N, Calderon FJ, Gonzalez-Lamuno D. MCT1 genetic polymorphism influence in high intensity circuit training: a pilot study. J Sci Med Sport. 2010;13:526-30.

4. Cupeiro R, Gonzalez-Lamuno D, Amigo T, Peinado AB, Ruiz JR, Ortega FB, Benito PJ. Influence of the MCT1-T1470A polymorphism (rs1049434) on blood lactate accumulation during different circuit weight trainings in men and women. J Sci Med Sport. 2012;15:541-7.

5. de Geus EJ, Bartels M, Kaprio J, Lightfoot JT, Thomis M. Genetics of regular exercise and sedentary behaviors. Twin Res Hum Genet. 2014;17:262-71.

6. de Vilhena e Santos DM, Katzmarzyk PT, Seabra AF, Maia JA. Genetics of physical activity and physical inactivity in humans. Behav Genet. 2012;42:559-78.

7. den Hoed M, Brage S, Zhao JH, Westgate K, Nessa A, Ekelund U, Spector U, Spector TD, Wareham NJ, Loos RJF. Heritability of objectively assessed daily physical activity and sedentary behavior. Am J Clin Nutr. 2013;98:1317-25.

8. Fedotovskaya ON, Mustafina LJ, Popov DV, Vinogradova OL, Ahmetov, II. A common polymorphism of the MCT1 gene and athletic performance. Int J Sports Physiol Perform. 2014;9:173-80.

9. Hallal PC, Andersen LB, Bull FC, Guthold R, Haskell W, Ekelund U. Global physical activity levels: surveillance progress, pitfalls, and prospects. Lancet. 2012;380:247-57.

10. Hallal PC, Azevedo MR, Reichert FF, Siqueira FV, Araújo CL, Victora CG. Who, when, and how much? Epidemiology of walking in a middle-income country. Am J Prev Med. 2005;28:156-61.

11. Hallal PC, Gomez LF, Parra DC, Lobelo F, Mosquera J, Florindo AA, Reis RS, Pratt M, Sarmiento OL. Lessons learned after 10 years of IPAQ use in Brazil and Colombia. J Phys Act Health. 2010;7 Suppl 2:S259-64. 
12. Helmerhorst HJ, Brage S, Warren J, Besson $\mathrm{H}$, Ekelund U. A systematic review of reliability and objective criterion-related validity of physical activity questionnaires. Int J Behav Nutr Phys Act. 2012;9:103.

13. Hepple RT. The role of 02 supply in muscle fatigue. Can J Appl Physiol. 2002;27:56-69.

14. Horta BL, Gigante DP, Goncalves H, Motta JVS, Mola CL, Oliveira IO, Barros FC, Victora CG. Cohort Profile Update: The 1982 Pelotas (Brazil) Birth Cohort Study. Int J Epidemiol. 2015.

15. Kambouris M, Ntalouka F, Ziogas G, Maffulli N. Predictive genomics DNA profiling for athletic performance. Recent Pat DNA Gene Seq. 2012;6:229-39.

16. Kohl HW, 3rd, Craig CL, Lambert EV, Inoue S, Alkandari JR, Leetongin G, Kahlmeier S. The pandemic of physical inactivity: global action for public health. Lancet. 2012;380:294-305.

17. Lean CB, Lee EJ. Genetic variations in the MCT1 (SLC16A1) gene in the Chinese population of Singapore. Drug Metab Pharmacokinet. 2009;24:469-74.

18. Lee IM, Shiroma EJ, Lobelo F, Puska P, Blair SN, Katzmarzyk PT. Effect of physical inactivity on major non-communicable diseases worldwide: an analysis of burden of disease and life expectancy. Lancet. 2012;380:219-29.

19. Licinio J, Caglayan S, Ozata M, Yildiz BO, de Miranda PB, O'Kirwan F, Whitby R, Liang L, Cohen O, Bhasin S, Krauss RM, Veldhuis JD, Wagner AJ, DePaoli AM, McCann SM, Wong ML. Phenotypic effects of leptin replacement on morbid obesity, diabetes mellitus, hypogonadism, and behavior in leptin-deficient adults. Proc Natl Acad Sci U S A. 2004;101:4531-6.

20. Loos RJ, Rankinen T, Tremblay A, Pérusse L, Chagnon Y, Bouchard C. Melanocortin-4 receptor gene and physical activity in the Quebec Family Study. Int J Obes (Lond). 2005;29:420-8.

21. Lopez-Fernandez I, Merino-Marban R, Fernandez-Rodriguez E. Examining the relationship between sex and motivation in triathletes. Percept Mot Skills. 2014;119:42-9.

22. Merezhinskaya N, Fishbein WN, Davis JI, Foellmer JW. Mutations in MCT1 cDNA in patients with symptomatic deficiency in lactate transport. Muscle Nerve. 2000;23:90-7.

23. Price AL, Patterson NJ, Plenge RM, Weinblatt ME, Shadick NA, Reich D. Principal components analysis corrects for stratification in genome-wide association studies. Nat Genet. 2006;38:904-9.

24. Sawczuk M, Banting LK, Cieszczyk P, Maciejewska-Karlowska A, Zarebska A, Leonska-Duniec A, Jastrzebski Z, Bishop DJ, Eynon N. MCT1 A1470T: A novel polymorphism for sprint performance? J Sci Med Sport. 2015:114-8.

25. Simonen RL, Rankinen T, Perusse L, Leon AS, Skinner JS, Wilmore JH, Rao DC, Bouchard C. A dopamine D2 receptor gene polymorphism and physical activity in two family studies. Physiol Behav. 2003;78:751-7.

26. Smith GD. Use of genetic markers and gene-diet interactions for interrogating population-level causal influences of diet on health. Genes Nutr. 2011;6:27-43.

27. Smith GD, Lawlor DA, Harbord R, Timpson N, Day I, Ebrahim S. Clustered environments and randomized genes: a fundamental distinction between conventional and genetic epidemiology. PLoS 
Med. 2007;4:e352.

28. Stefan N, Vozarova B, Del Parigi A, Ossowski V, Thompson DB, Hanson RL, Ravussin E, Tataranni PA. The GIn223Arg polymorphism of the leptin receptor in Pima Indians: influence on energy expenditure, physical activity and lipid metabolism. Int J Obes Relat Metab Disord. 2002;26:1629-32.

29. Symons Downs D, Savage JS, DiNallo JM. Self-determined to exercise? Leisure-time exercise behavior, exercise motivation, and exercise dependence in youth. J Phys Act Health. 2013;10:176-84.

30. Victora CG, Barros FC. Cohort profile: the 1982 Pelotas (Brazil) birth cohort study. Int J Epidemiol. 2006;35:237-42. 